\title{
Gender disparity in cardiovascular mortality following radiation therapy for Hodgkin's lymphoma: a systematic review
}

\author{
Yaser Khalid ${ }^{1 *}$ (D) Michael Fradley ${ }^{2}$, Neethi Dasu ${ }^{3}$, Kirti Dasu ${ }^{4}$, Ankit Shah $^{5}$ and Adam Levine 6
}

\begin{abstract}
Background: Radiation-induced coronary artery disease (R-CAD) has become an increasingly recognized phenomenon. Although the clinical relationship between radiation therapy and CAD risk is well known, there is minimal investigation of the gender relationship to radiation-induced CAD events and the resulting cardiovascular (CV) events/mortality. We study the gender variation in the incidence of CV events/mortality related to R-CAD in Hodgkin's Lymphoma (HL) patients.

Methods: The Preferred Reporting Items for Systematic Reviews and Meta-Analyses (PRISMA) guidelines were used in this systematic review and network meta-analysis. OVID, Cochrane Central Register of Controlled Trials via the Wiley Interface, Web of Science Core Collection, MEDLINE, EMBASE, and Google Scholar were investigated to identify prospective and retrospective observational studies comparing women and men following radiation treatment for Hodgkin's lymphoma. Ten studies were included (4 prospective, 6 retrospective). The primary outcome was incidence of cardiovascular events/mortality. The secondary outcome was all-cause mortality. Metaregression for age was also performed.
\end{abstract}

Results: Of 13,975 patients, including 41\% females and 59\% males, CV events/mortality were noted to be significantly higher in women compared to men (OR 3.74, 95\% Cl 2.44-5.72, $p<0.001)$. All-cause mortality was also higher in women compared to men (OR 1.94, 95\% Cl 1.10-3.44, $p<0.023)$. On meta-regression analysis, elderly populations have a higher rate of mortality, which was even higher for women than men (coefficient $=0.0458, p=$ 0.0374).

Conclusions: Women have a higher rate of R-CAD related CV events/mortality and all-cause mortality compared to men amongst radiation-treated patients. These data highlight the need for increased surveillance to better monitor for R-CAD in female patients treated with mantle or mediastinal radiation.

Keywords: Radiation, Hodgkin's lymphoma, Coronary artery disease, Women, Prevention

\footnotetext{
* Correspondence: ysksorosh1990@gmail.com

${ }^{1}$ Department of Internal Medicine, Memorial Healthcare System, Hollywood,

FL, USA

Full list of author information is available at the end of the article
}

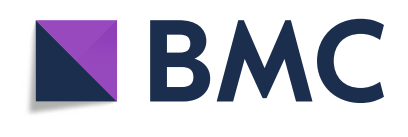

(c) The Author(s). 2020 Open Access This article is licensed under a Creative Commons Attribution 4.0 International License, which permits use, sharing, adaptation, distribution and reproduction in any medium or format, as long as you give appropriate credit to the original author(s) and the source, provide a link to the Creative Commons licence, and indicate if changes were made. The images or other third party material in this article are included in the article's Creative Commons licence, unless indicated otherwise in a credit line to the material. If material is not included in the article's Creative Commons licence and your intended use is not permitted by statutory regulation or exceeds the permitted use, you will need to obtain permission directly from the copyright holder. To view a copy of this licence, visit http://creativecommons.org/licenses/by/4.0/ The Creative Commons Public Domain Dedication waiver (http://creativecommons.org/publicdomain/zero/1.0/) applies to the data made available in this article, unless otherwise stated in a credit line to the data. 


\section{Introduction}

Radiation-induced coronary artery disease (R-CAD) has become an increasingly well recognized entity. R-CAD is one of the leading causes of morbidity and mortality amongst patients treated with radiotherapy for mediastinal malignancies, especially breast cancer and Hodgkin's lymphoma (HL) [1, 2]. The risk of R-CAD increases with the frequency and duration of radiation therapy and the amount of radiation used [1-5].

Of note, approximately 8480 people were diagnosed with HL in 2020 in the United States [3-5]. Nearly half of the patients do not have complete response to chemotherapy alone and require further salvage treatment with radiotherapy and/or autologous stem cell transplant for treatment [6, 7]. For decades, mantle or mediastinal field radiotherapy has been a therapeutic option with cure rates shown to be as high as $85 \%$, however, this therapy inadvertently leads to potential exposure of cardiac structures to radiation $[3,5]$. Patients who have survived such radiation treatments are now presenting with higher rates of R-CAD related events, such as myocardial infarction, heart failure, ischemic cardiomyopathy, and/or arrythmias, with complications generally occurring 5-10 years or longer after treatment [3-6, 8-10].

There are minimal studies examining the role of gender, especially as an independent, non-traditional risk factor for increased cardiovascular (CV) events/mortality among patients treated with radiation. In this systematic review and meta-analysis, we assess the role of gender in the incidence of $\mathrm{CV}$ events/mortality related to R-CAD in Hodgkin's Lymphoma (R-HL) patients who were treated with radiation.

\section{Methods}

\section{Search methods and study selection}

A systematic review and meta-analysis were performed following the Preferred Reporting Items for Systematic Reviews and Meta-Analyses (PRISMA) guidelines. Two co-authors (YSK and NRD) independently searched published studies indexed in OVID, Cochrane Central Register of Controlled Trials via the Wiley Interface, Web of Science Core Collection, MEDLINE, EMBASE, and Google Scholar from October 31, 2019 until April 1, 2020 thoroughly for the following keywords: "Radiation-Induced Coronary Artery Disease, Hodgkin's Lymphoma, Radiation, Mediastinal Tumors." Reviews, titles, abstracts, editorials were closely evaluated for the unrelated articles, which were subsequently excluded from our study. Research studies and articles published in all languages were considered.

All retrospective and prospective studies examining the rate of R-CAD in patients with HL were considered eligible. Only studies studying R-CAD with gender statistics were included. Adverse events, such as cardiovascular mortality and events, were defined by the standards of the Common Terminology Criteria for Adverse Events. The definition of cardiovascular events was a cardiac disorder that limited activities of daily living (ADLs) or proved to be life-threatening.

\section{Data extraction}

Furthermore, two co-authors (YSK and NRD) independently screened studies for the inclusion. In Excel, a data extraction table was utilized to compile and display the pertinent information from each article, which included the following: first author's last name, publication year, study design, country, duration of radiation treatment, sample size, number of patients for each gender, mean age of patients, median radiation dose, mortality from cardiovascular diseases or all-causes, and incidence of cardiovascular events (including myocardial infarction, abnormal stress test, received revascularization via coronary intervention or bypass, stroke, ventricular arrhythmias, heart failure, pericardial or valvular heart disease, and/or the presence of carotid intimal media thickness) were recorded. The table was constructed by the first author (YSK) and verified by one of the co-authors (NRD).

Finally, the Cochrane Risk of Bias Tool was employed to assess the risk of bias. Disagreements throughout this process were resolved by consensus of the entire team. When needed data was not directly found in the published articles, we obtained such data from the authors through response letters/ e-mail or via reviewing their supplemental reports. All of the authors were contacted.

\section{Meta-analysis}

The Hartung-Knapp-Sidik-Jonkman (HKSJ) method [11-13] was employed to complete the statistical analysis using MedCalc software (MedCalc Software Ltd., Belgium) with: 1) a summary of data from individual studies; 2) an investigation of the studies' heterogeneity graphically and statistically; 3) calculation of clustered indexes; and 4) graphical illustration via Forest Plots. Our assumption of heterogeneity was tested for each planned analysis using the Cochrane- $Q$ heterogeneity and $\mathrm{I}^{2}$ statistics with each of the following values: low (0-25\%), moderate (25-75\%), and high (>75\%). Random effects models using the Mantel-Haenszel method and fixed effects models were both used [14, 15]. Metaregression was analyzed using a generalization of Littenberg and Moses Linear model $[16,17]$ by inverse of the variance or study size unweighted. A secondary analysis was performed using the Der Simonian \& Laird method 
and fixed effects models [18] through the Comprehensive Meta-Analysis software (Additional file 1: Appendix A).

\section{Results}

\section{Baseline patient characteristics of included studies}

Figure 1 displays the methods by which the studies were chosen for our analysis. At first, literature investigation yielded a total of 488 studies that were considered for inclusion in the study. Review articles, case reports, retrospective studies, abstracts, studies with insufficient data, and articles with overlapping study populations and redundant data were removed. Then, a total of 10 studies were evaluated in the final analysis (Table 1). All studies were conducted in the USA, Europe, and Canada. Four studies were retrospective studies and 6 were prospective studies. The number of patients in each study varied, with over 6000 patients in the largest study and 40 patients in the smallest study. Among a total of 13,975 patients (41\% females and $59 \%$

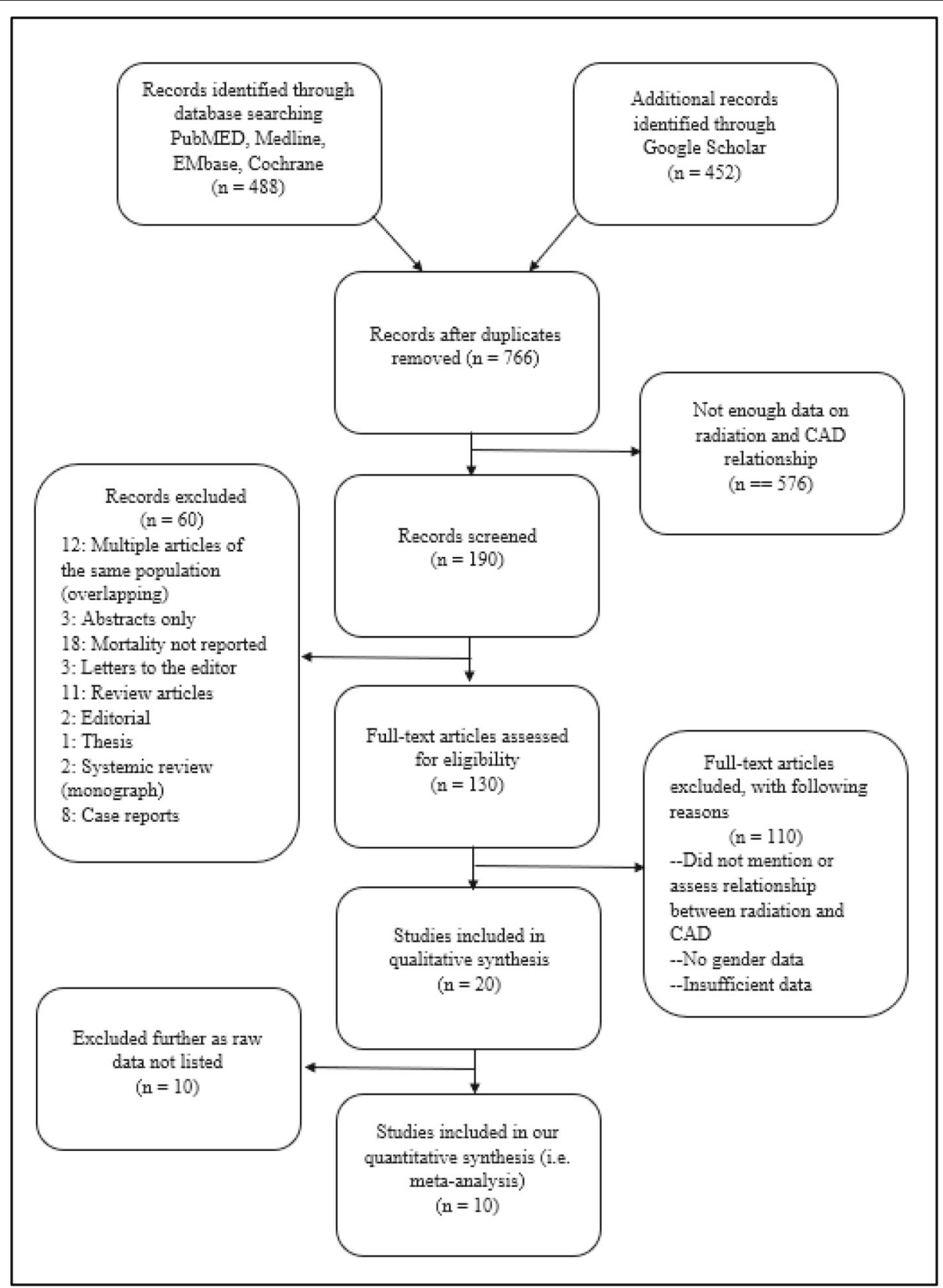

\section{CAD $=$ coronary artery disease}

Fig. 1 Prisma flow chart of studies screened and included in meta-analysis 
Table 1 List of Selected Studies with Their Demographics, Duration, Sample Size, Mean Age, Radiation Doses, and Cardiovascular Outcomes

\begin{tabular}{|c|c|c|c|c|c|c|c|}
\hline \multirow[t]{2}{*}{ Trial Information } & \multirow[t]{2}{*}{ Country } & \multirow[t]{2}{*}{ Duration } & \multicolumn{2}{|c|}{ Sample (\%) } & \multirow[t]{2}{*}{ Mean Age (Years) } & \multirow[t]{2}{*}{ Median Radiation Dose (Gy) } & \multirow[t]{2}{*}{ Outcome } \\
\hline & & & Female & Male & & & \\
\hline $\begin{array}{l}\text { Boivin 1982, [19] } \\
\text { Retrospective study }\end{array}$ & USA & 33.0 years & 44.2 & 55.8 & $<44$ & $>30$ & CV mortality \\
\hline $\begin{array}{l}\text { Galper 2011, [2] } \\
\text { Retrospective study }\end{array}$ & USA & 14.7 years & 53.6 & 46.4 & 47 & $>36$ & $\begin{array}{l}\text { CAD (MI, CABG, PTCA), } \\
\text { arrhythmias (AICD), } \\
\text { valvular disease, pericardial disease }\end{array}$ \\
\hline $\begin{array}{l}\text { Giancolo 2010, [20] } \\
\text { Prospective study }\end{array}$ & Italy & $\begin{array}{l}5.0 \\
\text { months }\end{array}$ & 46.4 & 53.6 & $47.8+/-17.4$ & $41.2+/-15.6$ & CIMT \\
\hline $\begin{array}{l}\text { Hahn 2017, [21] } \\
\text { Retrospective study }\end{array}$ & Canada & $\begin{array}{l}\text { One time } \\
\text { analysis }\end{array}$ & 39.2 & 60.8 & 34.2 & 25 & Ischemic CVD \\
\hline $\begin{array}{l}\text { Heidenreich 2007, [22] } \\
\text { Prospective study }\end{array}$ & USA & $\begin{array}{l}\text { One time } \\
\text { analysis }\end{array}$ & 45.4 & 54.6 & 42 & $>35$ & $\begin{array}{l}\text { Asymptomatic CAD stress testing, } \\
\text { followed by coronary angiography } \\
\text { if positive stress test }\end{array}$ \\
\hline $\begin{array}{l}\text { Hoppe } 1997,[23] \\
\text { Prospective study }\end{array}$ & USA & 35.0 years & 41.0 & 59.0 & NA & $>30$ & $\begin{array}{l}\text { Cardiac heart disease (pericarditis, } \\
\text { coronary artery disease, functional } \\
\text { valvular/conduction defects) }\end{array}$ \\
\hline $\begin{array}{l}\text { Hull 2003, [10] } \\
\text { Retrospective study }\end{array}$ & USA & 11.2 years & 39.0 & 61.0 & 25 & 33 & $\begin{array}{l}\text { CAD (Ml, CABG, PCl, > 75\% } \\
\text { stenosis) }\end{array}$ \\
\hline $\begin{array}{l}\text { Schellong 2010, [24] } \\
\text { Prospective study }\end{array}$ & $\begin{array}{l}\text { Germany, } \\
\text { Austria }\end{array}$ & 29.4 years & 41.7 & 58.3 & 27.9 & $>30$ & $\begin{array}{l}\text { Cardiac heart disease (pericarditis, } \\
\text { coronary artery disease, functional } \\
\text { valvular/conduction defects) }\end{array}$ \\
\hline $\begin{array}{l}\text { Swerdlow 2007, [25] } \\
\text { Prospective study }\end{array}$ & UK & 25.0 years & 38.1 & 61.9 & 34 & $>30$ & CVD mortality \\
\hline $\begin{array}{l}\text { Tsai } 2011,[26] \\
\text { Prospective study }\end{array}$ & Norway & $\begin{array}{l}20.0-24.0 \\
\text { years }\end{array}$ & 77.5 & 22.5 & $51+/-9$ & 41 & LV wall motion and EF, and CAD \\
\hline
\end{tabular}

Abbreviations: UK United Kingdom, CVD Cardiovascular Disease, CAD Coronary Artery Disease, MI Myocardial Infarction, CABG Coronary Artery Bypass Graft, PTCA Percutaneous Coronary Balloon Angiogram, AICD Automatic Intrac-cardiac Defibrillator, CIMT Common Carotid Intima-Media Thickness, $P C I$ Percutaneous Coronary Intervention, LV Left Ventricle, EF Ejection Fraction

males) from 10 studies with both patients with active cancer and cancer survivors, there was an average age of 40 years.

\section{Rates of cardiovascular events and mortality}

The aggregate incidence of both cardiovascular events and mortality was approximately 4-times higher in women compared to men (OR 3.74, 95\% CI 2.44-5.72, $p<0.001$ ) (Fig. 2). All-cause mortality was also almost 2times higher in women compared to men (OR 1.94, 95\% CI $1.10-3.44, p<0.023$ ) (Fig. 3). Similar results were noted both in the fixed- and random-effects models.

On meta-regression analysis (Fig. 4), both groups had higher mortality with advancing age, but this was even higher for women with definite increase of $\mathrm{CV}$ events/mortality at approximately 50 years of age that was statistically significant (coefficient = $0.0458, p=0.0374)$.

Funnel plot analysis (Additional file 1: Appendix C) displayed no asymmetry in the assessed outcomes $(p<$ 0.05 by Begg and Mazumdar's test or Egger's test). We have also performed $\mathrm{Q}$ and $\mathrm{I}^{2}$ analyses to assess for heterogeneity (Additional file 1: Appendix B).

\section{Discussion}

Currently, there is a paucity of studies specifically addressing gender disparity in $\mathrm{CV}$ mortality after radiation treatment for HL. Our study is the first systematic review and meta-analysis evaluating this disparity. Previously, mantle field or mediastinal radiation has been proven in several studies to significantly raise the risk for cardiovascular diseases independently of traditional cardiac risk factors as well $[4,8]$. Our analysis revealed that for women, such radiation therapy significantly raises $\mathrm{CV}$ events and mortality by almost four-fold and raises all-cause mortality by almost 2 -fold. This could be due to the underrepresentation of women in these clinical trials, likely higher doses of radiation needed to treat the Hodgkin's lymphoma for women, and a high degree of microvascular CAD in women.

Interestingly, studies have shown that the risk of CAD and related $\mathrm{CV}$ mortality increases when there are both traditional CV risk factors and radiation exposure $[8,10]$. For example, diabetes has been linked increased hospitalizations and hypertension and hyperlipidemia were two times as likely to develop ischemic cardiac disease among patients with R-HL [8, 22]. Our study further demonstrated that with aging, the 


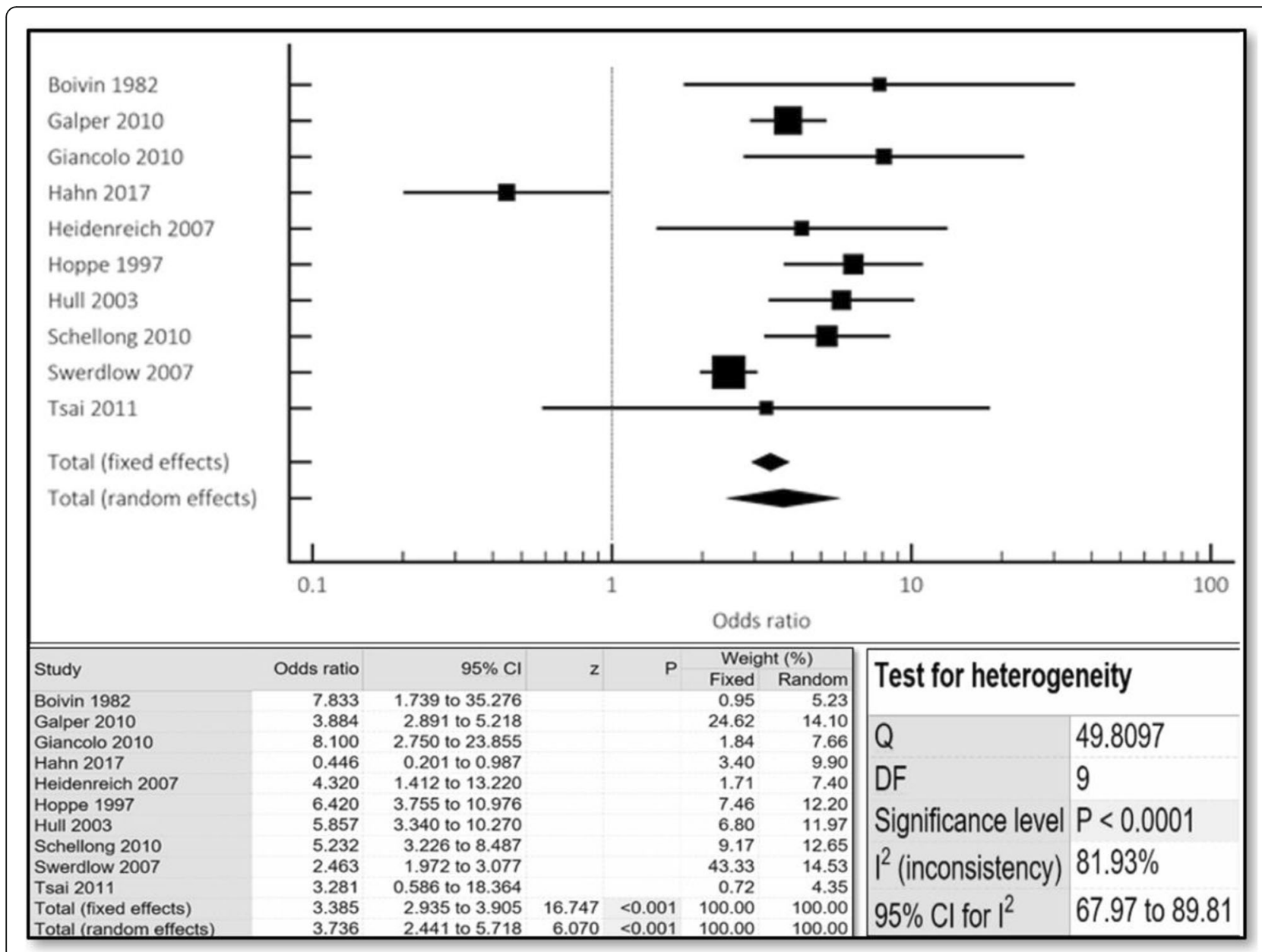

Fig. 2 Cumulative incidence of cv events/mortality noted in $\mathrm{r}$-hl females compared to males via combined fixed and random effects. Odds ratio, confidence interval and weight of studies for cv events/mortality for $r$-hl females compared to males via combined fixed and random effect. Test for heterogeneity of studies for $r$-hl females compared to males via combined fixed and random effects

incidence of CV events markedly increased for female patients. All the studies evaluated in this meta-analysis were independently corrected for the traditional cardiac risk factors for $\mathrm{CAD}$, like diabetes, hyperlipidemia, hypertension, and tobacco use. However, most of the studies did not clearly comment on the use of specific medical therapies for these conditions.

Additionally, high-dose mediastinal irradiation (cumulative dose of 35-40 Gy), increases cardiovascular disease and mortality in long-term survivors [24, 26, 27]. Mediastinal radiation treatment incidentally exposes a large quantity of the heart to radiation within the field, leading to increased risk of endothelial damage and promotion of atherosclerosis [25, 28]. In our analysis, most patients received over $30 \mathrm{~Gy}$ of radiation (Table 1). It should be recognized that in recent years, alterations to procedures and reductions in the radiation field volume have led to a significant reduction in cardiac exposure resulting in less cardiotoxicity than previously identified $[3,21]$.
The National Comprehensive Cancer Network currently recommends the following cardiovascular screening guidelines for survivors of HL to proactively reduce cardiovascular risk: annual blood pressure measurements, lipid panels, and serial serum glucose levels [23, 29, 30]. The American College of Radiology Appropriateness Criteria Expert Panel on Hodgkin Lymphoma Follow-up has broad recommendations: a stress test and an echocardiogram every 5 to 10 years after treatment as appropriate [1]. We suggest the development of specific screening guidelines for high risk patient groups treated with mantle field or mediastinal radiation, including female gender, radiation doses over $30 \mathrm{~Gy}$, concomitant use of cardiotoxic chemotherapy, and/or having one or more traditional $\mathrm{CV}$ risk factors.

\section{Study limitations}

We acknowledge certain limitations associated with this study. Since this is a study-level analysis, it is not 


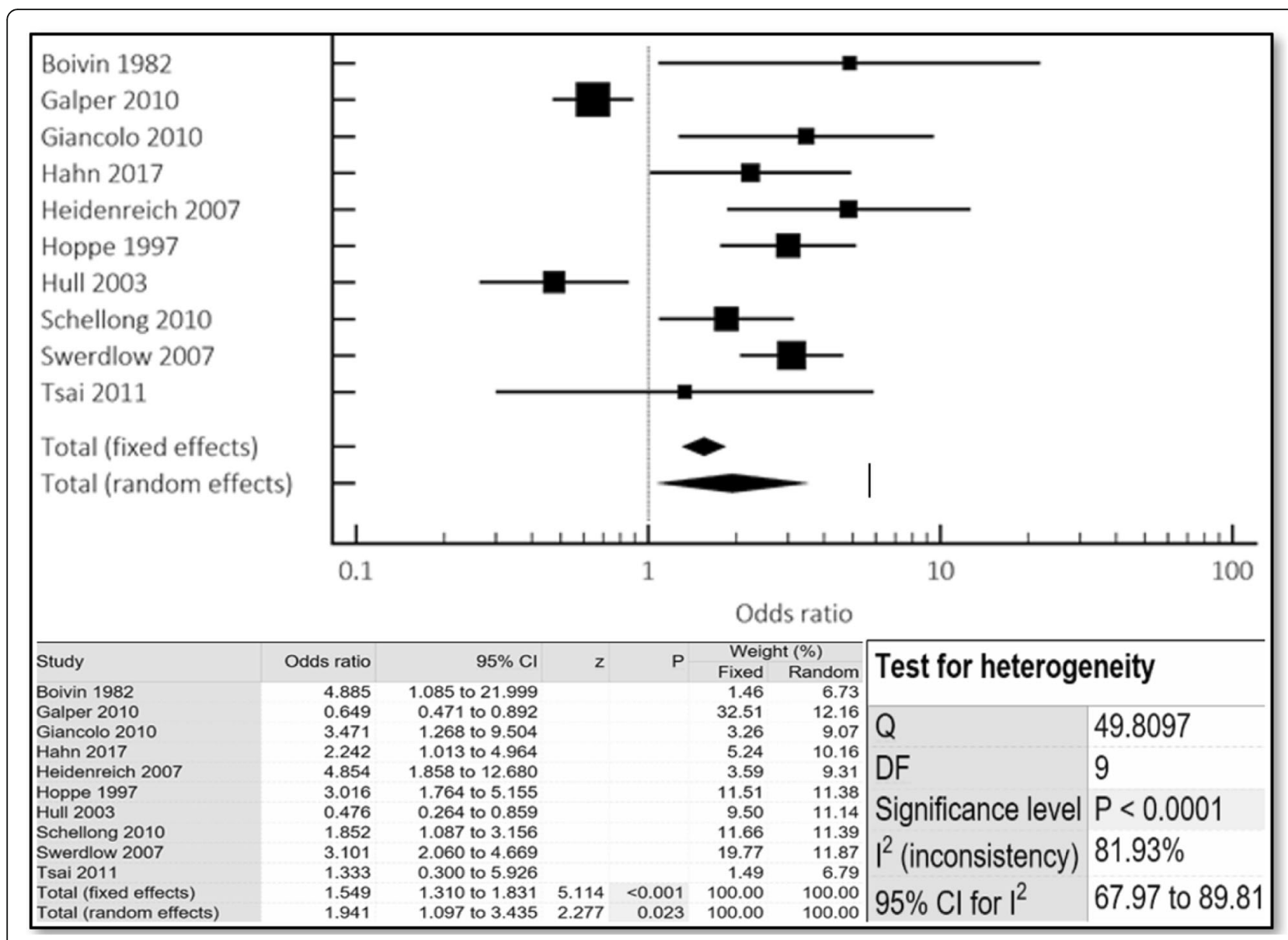

Fig. 3 Cumulative incidence of all-cause mortality noted in $\mathrm{r}$-hl females compared to males via combined fixed and random effects. Odds ratio, confidence interval and weight of studies for all-cause mortality for $r$-hl females compared to males via combined fixed and random effects. Test for heterogeneity of studies for $r$-hl females compared to males via combined fixed and random effects

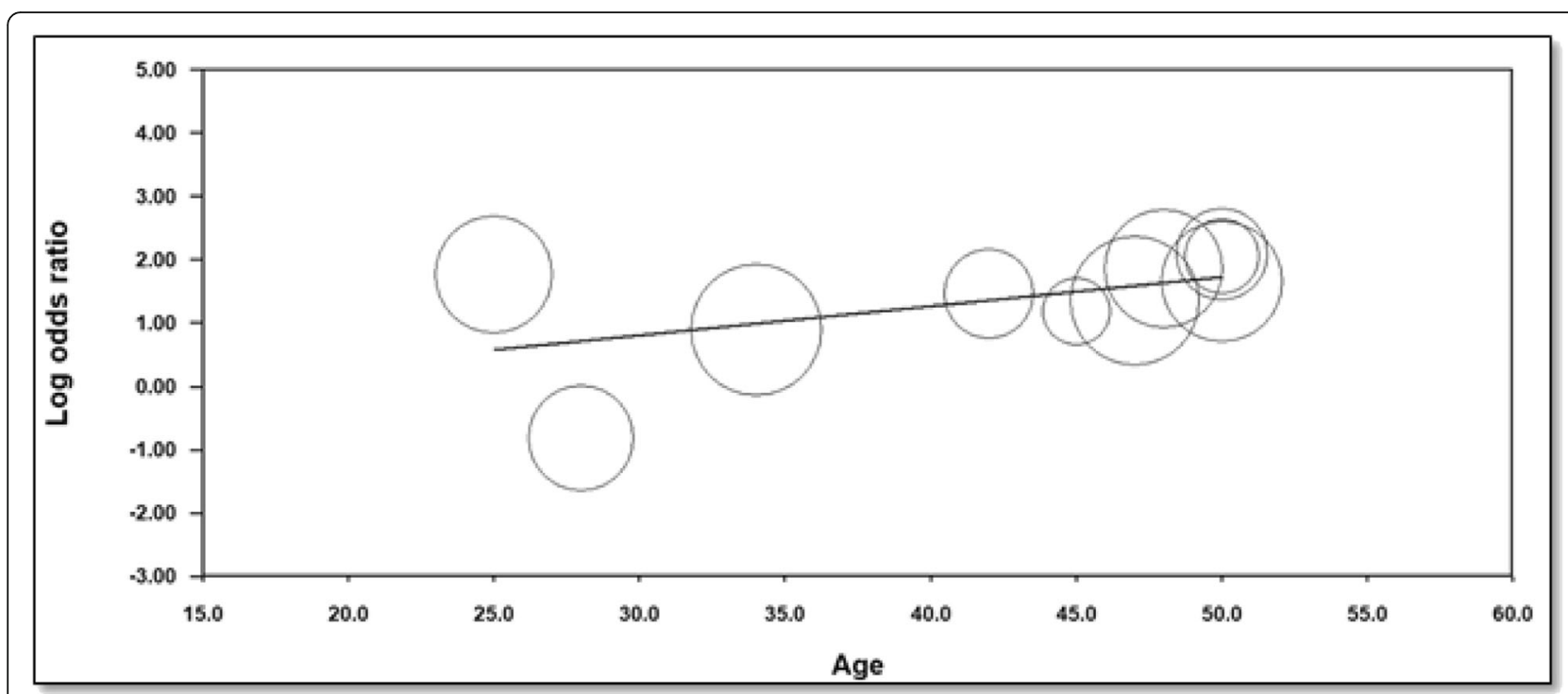

Fig. 4 Meta-regression to assess for incidence of cv events/mortality of radiation treated female patients with aging 
possible to make definitive conclusions about gender risks for patients with R-CAD. We identified only 10 retrospective and prospective observational cohort studies, accounting for an overall small sample size. None of the selected studies matched men and women with HL to radiation therapy dose, age of HL diagnosis, and how CVD was diagnosed. The studies did not specify the frequency and duration of radiation therapy for their patient populations. These findings may have led to a different course of CAD and subsequently CV mortality. Our study population mostly consisted of Caucasian nations. Most of the selected studies included young patients with a median age of 40 years. Unfortunately, most of the studies did not list when radiation was administered, total radiation dose received (only the average radiation dose), side of chest irradiated, concomitant chemotherapy, follow-up years after radiation therapy, methods to shield the heart during radiation, and presence of CV risk factors. All of these factors could affect the premature occurrence of radiation-induced CAD.

\section{Conclusions}

The risk of cardiovascular events and mortality is substantial for women with HL and R-CAD. Moreover, the rate of all-cause mortality was also higher in women compared to men. The findings demonstrate the need for vigilant screening for cardiovascular disease among cancer patients and survivors who have received mediastinal radiation. Future studies and analyses must focus on age, dose, duration of treatment, the mode of diagnosis for CVD as well as matching men and women with $\mathrm{HL}$ to radiation therapy dose, age at diagnosis, method of diagnosing CVD, and specify dose, frequency, and duration of radiation therapy. This will would allow researchers to make definitive conclusions regarding gender risks.

\section{Supplementary information}

Supplementary information accompanies this paper at https://doi.org/10. 1186/s40959-020-00067-7.

\section{Additional file 1.}

\section{Abbreviations}

R-CAD: radiation-induced coronary artery disease; HL: Hodgkin's lymphoma; $\mathrm{CV}$ : cardiovascular; OR: odds ratio; $\mathrm{Cl}$ : confidence interval

\section{Acknowledgements}

none.

\section{Authors' contributions}

The author(s) read and approved the final manuscript.

\section{Funding}

none.

Availability of data and materials Available.
Ethics approval and consent to participate

Not applicable.

Consent for publication

obtained.

\section{Competing interests}

none.

\section{Author details}

1 Department of Internal Medicine, Memorial Healthcare System, Hollywood, FL, USA. ${ }^{2}$ Cardio-Oncology Program, Division of Cardiovascular Medicine, Abramson Cancer Center, Perelman School of Medicine at the University of Pennsylvania, Philadelphia, USA. ${ }^{3}$ Department of Gastroenterology, Jefferson Health System NJ, Stratford, NJ, USA. Division of Biology, Syracuse University, Syracuse, NY, USA. ${ }^{5}$ Division of Cardiovascular Medicine, Rowan University School of Osteopathic Medicine at Jefferson Health System, Stratford, NJ, USA. ${ }^{6}$ Division of Interventional Cardiology, Virtua Lourdes Health System, Camden, NJ, USA

Received: 12 May 2020 Accepted: 17 July 2020

Published online: 05 August 2020

\section{References}

1. Cuomo JR, Javaheri SP, Sharma GK, Kapoor D, Berman AE, Weintraub NL. How to prevent and manage radiation-induced coronary artery disease. Heart Br Card Soc. 2018;104(20):1647-53.

2. Galper SL, Yu JB, Mauch PM, Strasser JF, Silver B, LaCasce A, et al. Clinically significant cardiac disease in patients with Hodgkin lymphoma treated with mediastinal irradiation. Blood. 2011;117(2):412-8

3. van Nimwegen FA, Schaapveld M, Janus CPM, Krol ADG, Petersen EJ, Raemaekers JMM, et al. Cardiovascular disease after Hodgkin lymphoma treatment: 40-year disease risk. JAMA Intern Med. 2015;175(6):1007.

4. Wethal T, Nedregaard B, Andersen R, Fosså A, Lund MB, Günther A, et al. Atherosclerotic lesions in lymphoma survivors treated with radiotherapy. Radiother Oncol. 2014;110(3):448-54.

5. Aleman BMP, Raemaekers JMM, Tirelli U, Bortolus R, van 't Veer MB, Lybeert MLM, et al. Involved-field radiotherapy for advanced Hodgkin's lymphoma. N Engl J Med. 2003;348(24):2396-406.

6. Moser EC. Long-term risk of cardiovascular disease after treatment for aggressive non-Hodgkin lymphoma. Blood. 2006;107(7):2912-9.

7. Andersson A, Näslund U, Tavelin B, Enblad G, Gustavsson A, Malmer B. Long-term risk of cardiovascular disease in Hodgkin lymphoma survivorsretrospective cohort analyses and a concept for prospective intervention. Int J Cancer. 2009;124(8):1914-7.

8. Myrehaug S, Pintilie M, Yun L, Crump M, Tsang RW, Meyer RM, et al. A population-based study of cardiac morbidity among Hodgkin lymphoma patients with preexisting heart disease. Blood. 2010;116(13):2237-40.

9. Maraldo MV, Giusti F, Vogelius IR, Lundemann M, van der Kaaij MAE, Ramadan S, et al. Cardiovascular disease after treatment for Hodgkin's lymphoma: an analysis of nine collaborative EORTC-LYSA trials. Lancet Haematol. 2015;2(11):e492-502.

10. Hull MC, Morris CG, Pepine CJ, Mendenhall NP. Valvular Dysfunction and Carotid, Subclavian, and Coronary Artery Disease in Survivors of Hodgkin Lymphoma Treated With Radiation Therapy. JAMA. 2003;290(21):2831. https://doi.org/10.1186/s40959-020-00067-7.

11. Hartung J, Knapp G. On tests of the overall treatment effect in meta-analysis with normally distributed responses. Stat Med. 2001;20(12):1771-82.

12. Hartung J, Knapp G. A refined method for the meta-analysis of controlled clinical trials with binary outcome. Stat Med. 2001;20(24):3875-89.

13. Sidik K, Jonkman JN. A simple confidence interval for meta-analysis. Stat Med. 2002:21(21):3153-9.

14. Mantel N. Chi-Square tests with one degree of freedom; extensions of the Mantel-Haenszel procedure. J Am Stat Assoc. 1963:58(303):690-700.

15. Mantel N, Haenszel W. Statistical aspects of the analysis of data from retrospective studies of disease. JNCI J Natl Cancer Inst. 1959;22(4):719-48.

16. Moses LE, Shapiro D, Littenberg B. Combining independent studies of a diagnostic test into a summary roc curve: data-analytic approaches and some additional considerations. Stat Med. 1993;12(14):1293-316. 
17. Littenberg B, Moses LE. Estimating diagnostic accuracy from multiple conflicting reports: a new meta-analytic method. Med Decis Mak. 1993;13(4): 313-21.

18. DerSimonian R, Laird N. Meta-analysis in clinical trials. Control Clin Trials. 1986;7(3):177-88.

19. Boivin J-F, Hutchison GB. Coronary heart disease mortality after irradiation for Hodgkin's disease. Cancer. 1982;49(12):2470-5.

20. Gianicolo ME, Gianicolo EAL, Tramacere F, Andreassi MG, Portaluri M. Effects of external irradiation of the neck region on intima media thickness of the common carotid artery. Cardiovasc Ultrasound. 2010;8(1):8.

21. Hahn E, Jiang H, Ng A, Bashir S, Ahmed S, Tsang R, et al. Late cardiac toxicity after Mediastinal radiation therapy for Hodgkin lymphoma: contributions of coronary artery and whole heart dose-volume variables to risk prediction. Int J Radiat Oncol. 2017;98(5):1116-23.

22. Heidenreich PA, Schnittger I, Strauss HW, Vagelos RH, Lee BK, Mariscal CS, et al. Screening for coronary artery disease after Mediastinal irradiation for Hodgkin's disease. J Clin Oncol. 2007;26(1):43-9.

23. Hoppe RT. Hodgkin's disease: complications of therapy and excess mortality. Ann Oncol. 1997;8:S115-8.

24. Schellong G, Riepenhausen M, Bruch C, Kotthoff S, Vogt J, Bölling T, et al. Late valvular and other cardiac diseases after different doses of mediastinal radiotherapy for hodgkin disease in children and adolescents: report from the longitudinal GPOH follow-up project of the German-Austrian DAL-HD studies. Pediatr Blood Cancer. 2010;55(6):1145-52.

25. Swerdlow AJ, Higgins CD, Smith P, Cunningham D, Hancock BW, Horwich A, et al. Myocardial infarction mortality risk after treatment for Hodgkin disease: a collaborative British cohort study. JNCI J Natl Cancer Inst. 2007; 99(3):206-14.

26. Tsai H-R, Gjesdal O, Wethal T, Haugaa KH, Fosså A, Fosså SD, et al. Left ventricular function assessed by two-dimensional speckle tracking echocardiography in long-term survivors of Hodgkin's lymphoma treated by Mediastinal radiotherapy with or without Anthracycline therapy. Am J Cardiol. 2011:107(3):472-7.

27. Jones LW, Liu Q, Armstrong GT, Ness KK, Yasui Y, Devine K, et al. Exercise and risk of major cardiovascular events in adult survivors of childhood Hodgkin lymphoma: a report from the childhood cancer survivor study. J Clin Oncol. 2014:32(32):3643-50.

28. Castellino SM, Geiger AM, Mertens AC, Leisenring WM, Tooze JA, Goodman $\mathrm{P}$, et al. Morbidity and mortality in long-term survivors of Hodgkin lymphoma: a report from the Childhood Cancer Survivor Study. Blood. 2011; 117(6):11.

29. Ng AK, Bernardo MVP, Weller E, Backstrand K, Silver B, Marcus KC, et al. Second malignancy after Hodgkin disease treated with radiation therapy with or without chemotherapy: long-term risks and risk factors. Blood. 2002; 100(6):1989-96.

30. Kupeli S. Risks and diagnosis of coronary artery disease in Hodgkin lymphoma survivors. World J Cardiol. 2014;6(7):555

\section{Publisher's Note}

Springer Nature remains neutral with regard to jurisdictional claims in published maps and institutional affiliations.

Ready to submit your research? Choose BMC and benefit from:

- fast, convenient online submission

- thorough peer review by experienced researchers in your field

- rapid publication on acceptance

- support for research data, including large and complex data types

- gold Open Access which fosters wider collaboration and increased citations

- maximum visibility for your research: over $100 \mathrm{M}$ website views per year

At $\mathrm{BMC}$, research is always in progress.

Learn more biomedcentral.com/submissions 